\title{
6 Materialität, Präsenz und Habitus: Wie Botschaften gemacht werden
}

\subsection{Fallbeispiel 3: Zwei praefecti annonae und ihre Inschriften}

Jede Inschrift war auch eine Botschaft. Wann immer ein inschriftliches Monument im öffentlichen Raum zur Aufstellung kam - sei es die Abschrift eines kaiserlichen Dekrets auf dem Forum, eine Stiftungsinschrift an einem Theater oder eine Ehreninschrift am Bildnis eines Magistraten -, so war damit eine konkrete Mitteilung verbunden, welche nicht nur an das lesende (also das rezipierende), sondern auch an das betrachtende (also das perzipierende) Publikum gerichtet war. Denn in Inschriften war weit mehr zu ,lesen' als es der bloße Inhalt des Texts wiedergeben konnte: Aus dem kaiserlichen Dekret, in der Regel auf einer großen Bronzetafel niedergeschriebenen, sprachen amtliche Autorität und staatliche Ordnung. Die in monumentalen Lettern an der Fassade angebrachte Stiftungsinschrift bezeugte die hohe soziale Stellung des Bauherren, dem das Privileg zuteil wurde, sich in das visuelle Gedächtnis der Gemeinde einzuschreiben. Und die Ehreninschrift des Magistraten diente nicht nur dazu, über den Namen und die Laufbahn des Porträtierten zu informieren, sondern zeichnete im Zusammenspiel mit der Statue ein absichtsvoll konzipiertes Bild eines bestimmten Habitus und Rollenverständnisses. So fand die Botschaft einer Inschrift nicht nur auf der Ebene des Textinhalts ihren Ausdruck, sondern auch auf der Ebene ihres äußeren Erscheinungsbilds und ihres räumlichen Settings, also: auf der Ebene der Materialität und der Präsenz. Von welcher Bedeutsamkeit diese beiden Kategorien für die Wirkung und Effektivität eines inschriftlichen Denkmals waren, war das Thema der beiden vorangegangenen Kapitel. Inwiefern Materialität, Präsenz und Botschaft voneinander abhingen, sich gegenseitig beeinflussten und überlagerten, soll nun anhand eines ausgewählten Fallbeispiels aus dem spätantiken Ostia vor Augen geführt werden, an dem sich sehr anschaulich nachvollziehen lässt, wie sich das Konzept der Materialität mit demjenigen der Präsenz zu einem umfassenden Programm persönlicher Repräsentation vereinte.

Die Rahmenhandlung unseres Beispiels bilden die im 4.Jh. durchgeführten Bau- und Restaurierungsmaßnahmen an den großen Forums-Thermen von Ostia, für welche die beiden Beamten Flavius Octavius Victor und Ragonius Vincentius Celsus, beide praefecti annonae von Rom und kraft dieses Amts auch für die öffentliche Bau-

Die Ergebnisse dieses Kapitels wurden 2012 im Rahmen der internationalen Konferenz „The Materiality of Text - placement, perception, presence“ in Durham vorgestellt und sind in Form eines englischsprachigen Beitrags in den daraus hervorgegangenen Tagungsakten als Bolle 2018 veröffentlicht. 
tätigkeit in Ostia zuständig, Verantwortung trugen. ${ }^{649}$ Der erste ließ die Thermen im beginnenden 4. Jh. baulich umgestalten, der zweite gegen Ende dieses Jahrhunderts. Beide hielten ihre Aktivitäten als Bauherren in Form mehrerer Inschriften und inschriftlicher Denkmäler fest, die sie innerhalb der Anlage und in der unmittelbaren Umgebung zur Aufstellung brachten. Welche Strategie sie dabei zugrunde legten, für welche Art von inschriftlichen Monumenten sie sich entschieden und wie sie diese dem Betrachter präsentierten, hätte unterschiedlicher kaum sein können. Obwohl zu ähnlichen Anlässen und mit einem Abstand von kaum 50 Jahren errichtet, zeichneten sich die jeweiligen Stücke durch eine bemerkenswert andersartige Materialität und Präsenz aus und waren als solche nicht nur Spiegelbild zweier verschiedener Persönlichkeiten, sondern auch Träger verschiedener Botschaften.

\subsection{Der Kontext: Die Forums-Thermen im 4. Jahrhundert}

Die Forums-Thermen lagen im Zentrum der Stadt, direkt südöstlich des Hauptforums. Sie waren während der wirtschaftlichen und kulturellen Blütezeit Ostias im 2. Jh. errichtet worden und stellten mit einer Fläche von mehr als 3.000 Quadratmetern die größte Anlage ihrer Art in der Stadt dar (Abb. 78). ${ }^{650}$

Sie bestanden aus einem weitläufigem Komplex von zwei hallenartigen Eingangsräumen (Räume 2 und 3), mehreren Umkleideräumen (apodyteria) und einem großen, im Zentrum gelegenem Kaltbaderaum mit zwei gegenüberliegenden Becken im Norden (frigidarium, Raum 4), an den sich eine Reihe von stufenartig aneinandergesetzten Heiß- und Warmbädern (caldaria, tepidaria) sowie von Schwitzräumen (sudatoria) nach Süden hin anschloss. Davor erstreckte sich eine großzügig angelegte Palästra von trapezförmigem Grundriss. In der Südwestecke der Freifläche befanden sich zwei kleine Sakralbauten, ${ }^{651}$ die Ränder des Platzes wurden durch eine Portikus

649 Etwa seit der Mitte des 3. Jhs. bekleidete der praefectus annonae Urbis Romae auch das Amt des curator rei publicae Ostiniensum und war als solcher für die Verwaltung Ostias zuständig. Dazu gehörte auch die Aufsicht über das öffentliche Bauwesen, weswegen seit eben jener Zeit nahezu ausschließlich die praefecti annonae als Stifter bzw. Verantwortliche für gemeinschaftlich genutzte Gebäude oder die (Wieder-)Errichtungen von Statuen zum Dekor der Stadt auftraten. Ein konkretes Datum für die Einrichtung dieses Doppelamtes ist nicht auszumachen; s. hierzu Meiggs 1960, 186; Gering 2004, 372f. Anm. 163.

650 Die grundlegende Publikation der Thermenanlage wurde von P. Cicerchia und A. Marinucci in der Reihe Scavi di Ostia vorgelegt: Cicerchia/Marinucci 1992. Sie enthält umfangreiche Informationen zur Baugeschichte und den einzelnen Bauphasen wie auch zur Architekturdekoration und den in der Anlage gefundenen Skulpturen und Inschriften. Zur architektonischen Gestaltung und der Baudekoration s. Pensabene 2007, 268-275; speziell zur spätantiken Phase der Anlage s. Poccardi 2006.

651 Dabei handelt es zum einen um einen Podiumstempel mit Pronaos und jeweils drei Statuennischen an den Seitenwänden und zum anderen um einen noch kleineren Bau, von dem allerdings lediglich die Fundamente, ein Bruchstück des Altars sowie Überreste der Terrakottaverkleidung er- 


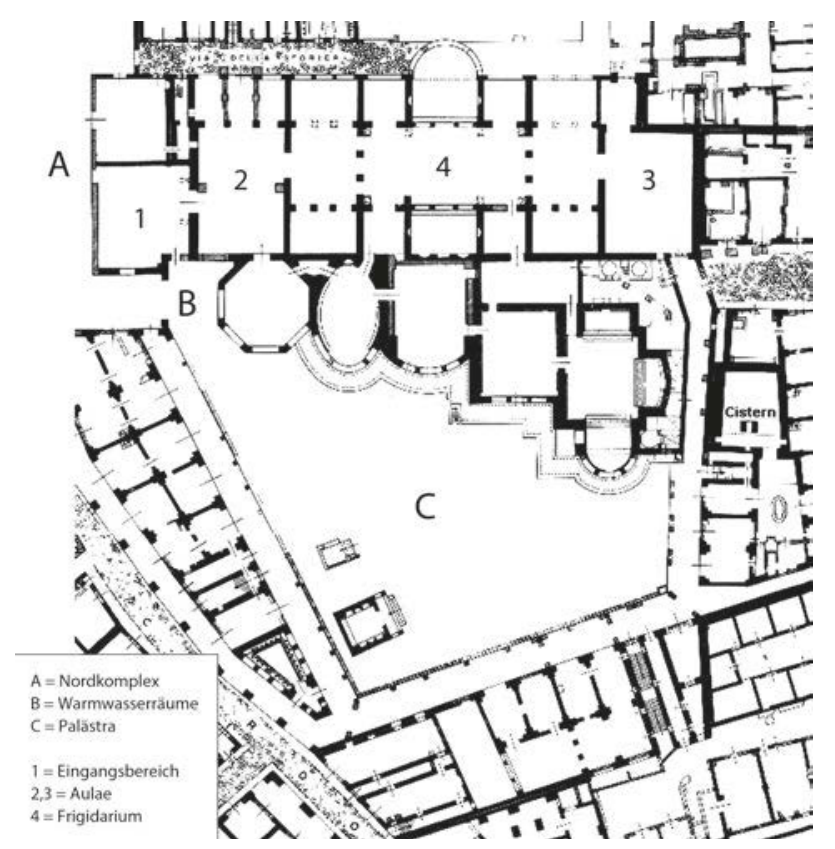

Abb.78: Forums-Thermen von Ostia, Grundriss.

gesäumt. Die Außenmauern und Wände des Thermenbaus bestanden aus rotbraunem Ziegelmauerwerk, für die Wandverkleidung im Inneren, die Säulen und Kapitelle sowie das Gebälk wurde weißer und farbig geäderter Marmor verwendet. Einige Räume waren mit einem Mosaikboden ausgestattet, der vornehmlich in Schwarz-Weiß gehaltene geometrische Dekorationsmotive zeigte. Zahlreiche Skulpturen dekorierten die verschiedenen Räume und Badebecken, darunter etwa ein Statuenpaar des Asklepios und der Hygieia sowie eine Statue der Fortuna. ${ }^{652}$ In der Palästra bewegte sich der Besucher zwischen Ehrenstatuen und Standbildern von Athleten und Sportlern, von denen sich etwa der Kopf eines Pugilisten erhalten hat. ${ }^{653}$

Für die Errichtung der Badeanlage im 2. Jh. hatte der aus dem Ritterstand stammende Staatsbeamte Marcus Gavius Maximus gesorgt, der unter Antoninus Pius das Amt des praefectus praetorio in Rom bekleidete. ${ }^{654}$ Die anlässlich der Einweihung

halten geblieben sind. Beide Bauten sind bis heute nur unzureichend publiziert, s. Meiggs 1960, 415; Pavolini 1983, 108. Zu dem Terrakotta-Antepagmentum mit der Darstellung einer stiertötenden Diana s. Cicerchia/Marinucci 1992, 153. - Die Tempelchen stammen offenbar aus dem 2. Jh. und spielten vielleicht in der Kultpraxis einer der ortsansässigen Athletengilden eine Rolle, so jedenfalls Steuernagel 2005, 79.

652 Cicerchia/Marinucci 1992, 147f. A 3 und A 4; 152f. A 20.

653 Cicerchia/Marinucci 1992, 155 A 27. Sämtliche Statuenfunde aus dem Thermenkomplex und der Palästra sind publiziert bei ebd. 145-157. Ob alle Stücke tatsächlich in den Thermen aufgestellt waren oder erst zu einem späteren Zeitpunkt hierher gelangten, etwa um als Baumaterial wiederverwendet zu werden, ist in manchen Fällen unklar.

654 PIR $^{2}$ G 104. 
der Anlage errichte Bauinschrift mit seinem Namen ist zwar nicht überliefert. Es hat sich aber eine Restaurierungsinschrift späterer Zeit erhalten, in der Marcus Gavius Maximus als Namensgeber des Bades genannt wird:

Vetustatis incur[ia---] conf[i]rm[atis --- ther]mis Gavi Ma[ximi ---] / dominorum nost[rorum ---] aete[r]no[rum principum --- loca proxi]ma fori et ian[uae ---]. ${ }^{65}$

Die Inschrift wurde auf einem Architrav angebracht, dessen genauer Anbringungsort in den Thermen jedoch nicht mehr nachzuvollziehen ist. Der Paläographie nach zu urteilen, gehört die Inschrift in das 4. Jh. und damit in eine Zeit, als es tatsächlich zu mehreren Umbau- und Renovierungsmaßnahmen in der Anlage kam. Ob diese allerdings wirklich aufgrund des hohen Alters und des baufälligen Zustands der Thermen notwendig waren, wie es die Inschrift glauben machen will, ist ungewiss. Insbesondere in der Spätantike war eine solche Rhetorik nachgerade topisch, und in auffällig vielen Inschriften dieser Zeit wird der drohende Verfall eines Gebäudes als Grund für die durchgeführten Baumaßnahmen genannt - und dies auch dann, wenn der wahre Anlass des Bauprojekts nicht etwa dem vermeintlich schlechten Zustand des Gebäudes, sondern vielmehr dem persönlichen Selbstdarstellungsbedürfnis des jeweiligen Bauherren geschuldet war. ${ }^{656}$ Und auch in unserem Fall müssen wir den Wortlaut der spätantiken Inschrift wohl nicht allzu wörtlich nehmen, denn in der Tat konzentrierten sich die Bauarbeiten des 4. Jhs. im Wesentlichen auf die architektonische Umgestaltung einzelner Bereiche der Thermenanlage und betrafen vor allem die Erneuerung der Marmordekoration, während substantielle Wiederherstellungsmaßnahmen und Instandsetzungsarbeiten nicht durchgeführt wurden.

Der erste, der sich in dieser Hinsicht hervortat, war im frühen 4. Jh. Flavius Octavius Victor. ${ }^{657}$ Er widmete sich zunächst der Portikusanlage der Palästra, die mit neuen Säulen aus Granit ausgestattet wurde. Das Kernstück seiner Baumaßnahmen aber betraf den Bereich des Frigidariums (Raum 4). Dort ließ er das nördliche der beiden Becken durch eine große Apsis erweitern, welche sich über die gesamte Breite der vorbeiführende Via della Forica erstreckte und die Straße somit an dieser Stelle einschnitt

655 AE 1955, 287; Bloch 1953; Meiggs 1960, 415; Cicerchia/Marinucci 1992, 216-219 C 106, fig. 148; Cébeillac-Gervasoni/Caldelli/Zevi 2006, 145 Nr. 29.3.2. Eine präzisere Datierung der Inschrift ist kaum möglich. Cicerchia/Marinucci 1992, 217 schlugen vor, die wenigen auf einem wohl zugehörigen Fragment erhaltenen Buchstaben zu [---]ITO[---] / [---Ho?]nor[i-? ---] zu ergänzen und die Inschrift folglich in die Regierungszeit des Honorius (395-423) zu datieren, wofür es allerdings keine weiteren Belege gibt. - Abgesehen von der Architravinschrift haben sich im Bereich der Palästra noch mehrere fistulae mit dem Namen des Marcus Gavius Maximus und seinem Titel gefunden: M. Gavi Maximi pr(aefecti) pr(aetorio) e(minentissimi); s. hierzu Cicerchia/Marinucci 1992, 222 C 109 $\alpha$, tav. XIV, fig. 151; Bruun 1995, 58; Cébeillac-Gervasoni/Caldelli/Zevi 2006, 144f. Nr. 29.3.1.

656 Vgl. hierzu o. S.42f.

657 PLRE I 638 s. v. Fl. Octavius. 
und blockierte. Gleichzeitig sorgte er dafür, dass die Becken mit einer neuen Marmorverkleidung und das Innere mit neuen Säulen und Kapitellen ausgestattet wurden. ${ }^{658}$

Gegen Ende des Jahrhunderts war es dann Ragonius Vincentius Celsus, unter dessen Ägide die Thermen ein weiteres Mal umgestaltet wurden. Das Hauptaugenmerk seiner Baumaßnahmen lag nunmehr auf den Eingangsbereichen und auf der dem Forum zugewandten Außenfassade. Ursprünglich war man über die Via della Forica in die Thermen gelangt und hatte den Bau von Norden her über die zwei hallenartigen Räume 2 und 3 betreten. ${ }^{659}$ Diese Zugänge wurden nun geschlossen und durch zwei neue Eingänge im Westen ersetzt. Von nun an bildete Raum 1 den Hauptzugang in die Thermen, der nun die Funktion eines Atriums übernahm, von dem aus man sowohl zu den Baderäumen im Nordkomplex als auch in die Palästra gelangte. ${ }^{660}$

\subsection{Die Denkmäler: Die Inschriften des Flavius Octavius Victor und des Ragonius Vincentius Celsus}

Beide Bauherren ließen an ihre Initiative durch Denkmäler und Inschriften erinnern, welche nach Abschluss der Baumaßnahmen in den von ihnen neu gestalteten Bereichen der Anlage errichtet wurden. Dabei handelte es sich sowohl um monumentale Bautituli am Gebälk wie auch um Inschriften auf Tafeln und Basen, die im Zusammenhang mit Statuenaufstellungen errichtet wurden.

Von Flavius Octavius Victor sind insgesamt fünf Stücke bekannt: zwei fragmentarisch erhaltene opistographe Marmortafeln, ein kleines Bruchstück eines Marmorblocks mit sehr lückenhafter Inschrift sowie zwei ebenfalls in Fragmenten überlieferte Bauinschriften, für deren Anbringung man auf bereits vorhandene Architrave aus dem Bad zurückgegriffen hatte:

1. Zwei Fragmente einer Tafel aus weißem Marmor, beidseitig beschriftet, gefunden nahe den Grandi Horrea. Maße: ca. 88,5 × 28,5 ×3 cm bzw. ca. 15,5 $\times 23 \times 3 \mathrm{~cm}$, Buchstabenhöhe Seite A: ca. 3-4 cm; Buchstabenhöhe Seite B: ca. 4-5 cm (Abb. 79). ${ }^{661}$

$658 \mathrm{Zu}$ den Baumaßnahmen unter Flavius Octavius Victor s. Meiggs 1960, 551; Cicerchia/Marinucci 1992, 71-73; Pensabene 2007, 275; Lavan 2012, 659-662.

659 Ein weiterer Eingang befand sich im Osten über die Semita Horreorum, der von den Umbaumaßnahmen allerdings nicht betroffen war.

$660 \mathrm{Zu}$ den Baumaßnahmen unter Ragonius Vincentius Celsus s. Meiggs 1960, 551; Cicerchia/Marinucci 1992, 51; Pensabene 2007, 273; Lavan 2012, 654.

661 CIL XIV 4714 = CLE 2049 = AE 1920, 94a; Zevi 1971, 466; Cicerchia/Marinucci 1992, 216 C 105; aufbewahrt im Museo Archeologico di Ostia (Inv.-Nr. 11918). 

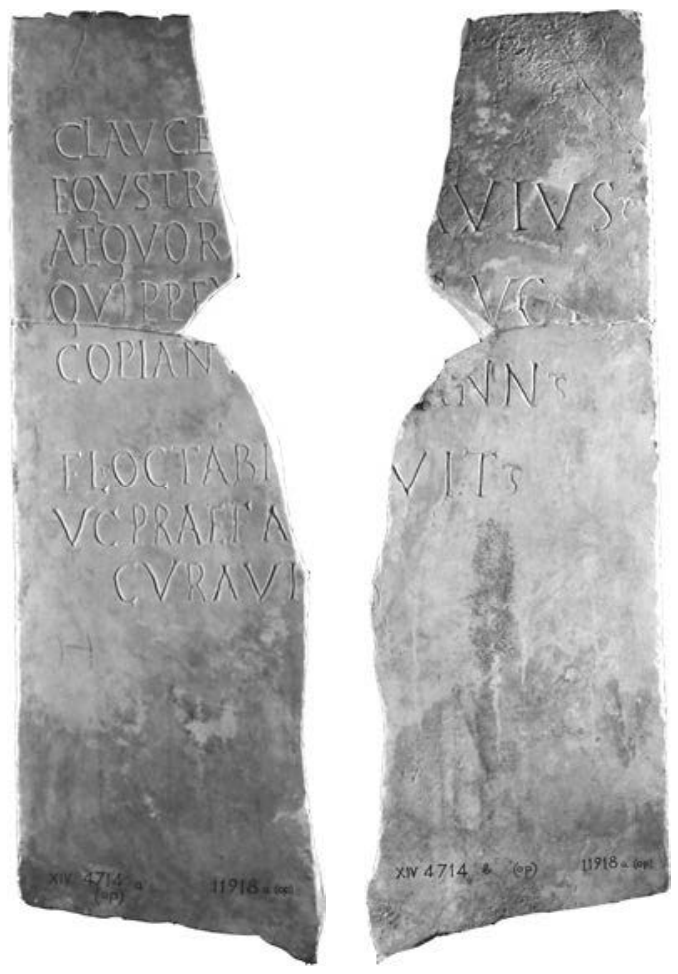

Abb.79a-b: Opistographe Marmortafel von einer Statuengruppe der Glauke mit einem Seepferd, Vorder- und Rückseite.

Seite A:

Glauce[n v]ectat / equ(u)s tra[mi]ttens / aequora [n]ando / quippe v[ehi remis] / copia nu[lla datur] / Fl(avius) Octabi[us] / v(ir) c(larissimus) / praef(ectus) a[nn(onae)] / curavi[t].

Die Glauke trägt ein Pferd, das schwimmend die Meere durchläuft, da ihr keine Gelegenheit zuteil wird, zu Schiff zu reisen. Flavius Octavius, vir clarissimus und Getreidepräfekt, sorgte (für die Aufstellung dieses Bilds).

Seite B:

[Fl(avius) Oct]avius /[Victor] v(ir) c(larissimus) / [praef(ectus)] ann(onae) / [cura]vit. ${ }^{662}$

Flavius Octavius, vir clarissimus und Getreidepräfekt sorgte (für die Aufstellung dieses Bilds).

Wie aus dem kurzen Epigramm auf Seite A hervorgeht, gehörte die Tafel offenbar zu einer Statuengruppe, welche die Meeresnymphe Glauke zusammen mit ihrem Reittier, einem Hippocampus, zeigte. Wer das Bildwerk hatte errichten lassen, war unterhalb der kurzen Verse sowie noch einmal auf der anderen Seite der Tafel zu lesen. Es war der vir clarissimus Flavius Octavius Victor in seiner Rolle als praefectus annonae.

662 Interessanterweise entschied man sich bei Seite A für die Schreibweise Octabius, bei Seite B aber für die Form Octavius. 

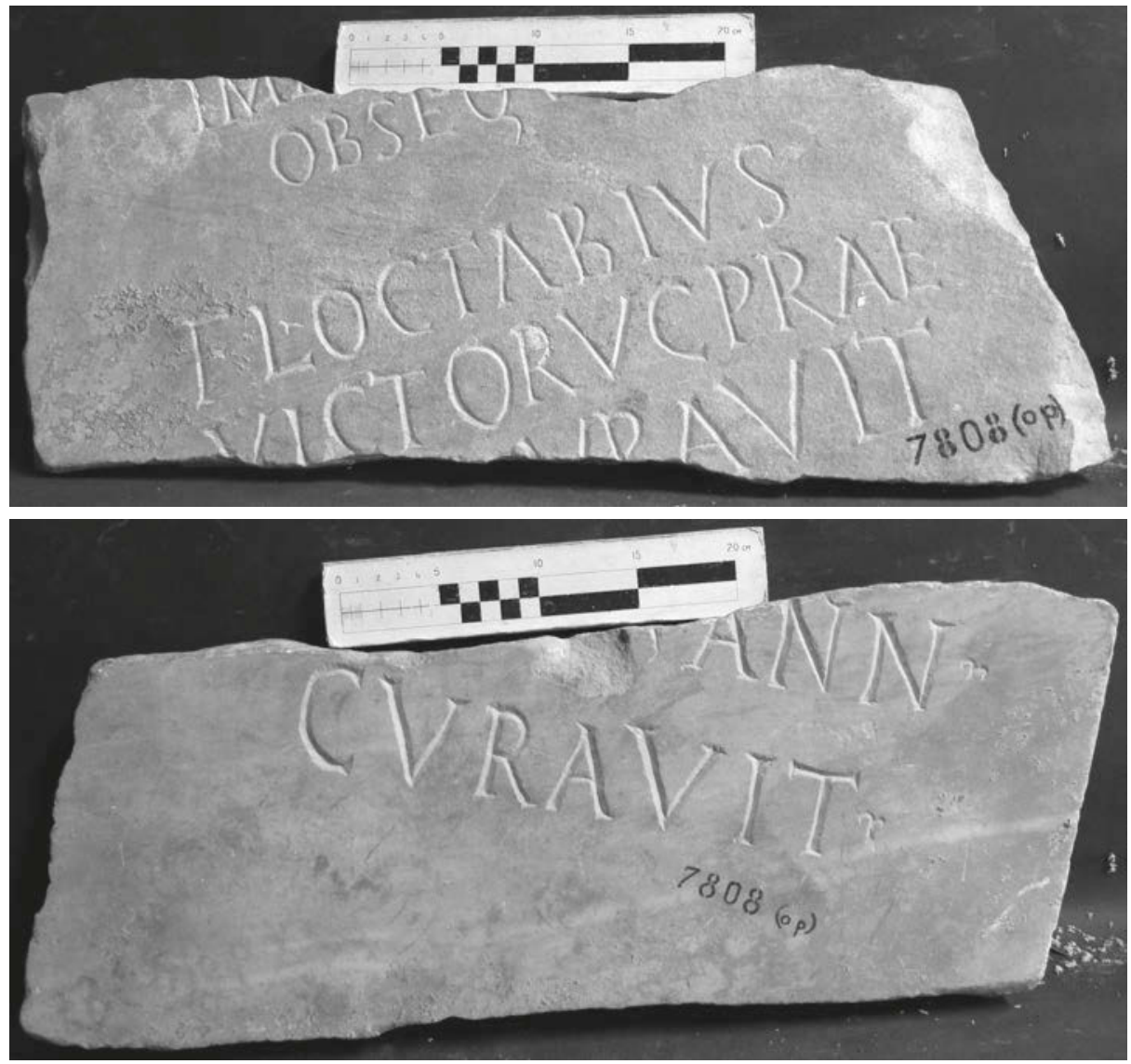

Abb. 80a-b: Fragment einer opistographen Marmortafel mit der Inschrift des Fl. Octavius Victor, Vorder- und Rückseite.

2. Fragment einer Tafel aus grau geädertem Marmor, beidseitig beschriftet, gefunden nahe den Horrea dell'Artemide. Maße: ca. 34,5 $49 \times 3,5 \mathrm{~cm}$, Buchstabenhöhe Seite A: ca. 3,5-4,5 cm, Buchstabenhöhe Seite B: ca. 4,5-5,3 cm (Abb. 80). ${ }^{663}$

Seite A:

[----]/Im[---]/obsequ[---] / Fl(avius) Octabius / Victorv(ir) c(larissimus) praef(ectus) / [ann(onae) c]uravit.

Seite B:

[Fl(avius) Octavius / Victor v(ir) c(larissimus) / praef(ectus)] ann(onae) / curavit.

663 Ohne Eintrag in CIL oder AE, publiziert bei Cicerchia/Marinucci 1992, 216 C 105; s. auch Zevi 1971, 466f. n. 47; aufbewahrt im Museo Archeologico di Ostia (Inv.-Nr. 7808). 
Auch in diesem Fall wird es sich um eine Inschriftentafel gehandelt haben, die ein von Flavius Octavius Victor errichtetes Bildwerk begleitete. Dessen Gestalt lässt sich aufgrund des fragmentarischen Erhaltungszustands allerdings nicht mehr nachvollziehen (so das Bildthema in der Inschrift überhaupt genannt wurde). Ein der Statuengruppe ähnliches, zum Ambiente einer Thermenanlage passendes Sujet ist am wahrscheinlichsten. Auch hier war die formularhafte Wendung mit dem Namen und dem Titel Victors noch einmal auf der zweiten Seite eingeschrieben.

Obwohl die Fragmente der beiden Tafeln außerhalb der Forums-Thermen gefunden wurden, kann kein Zweifel daran bestehen, dass sie im Zusammenhang mit den Umbau- und Renovierungsmaßnahmen Victors am Frigidarium entstanden und einst an Ort und Stelle zu sehen waren. Dafür spricht zum einen das Bildthema der Meeresnymphe mit ihrem Seepferd und zum anderen die Tatsache, dass es keinerlei Belege für weitere Bau- oder Stiftungsaktivitäten des Victor in Ostia gibt, mit denen die Inschriften in Verbindung gestanden haben könnten. Wahrscheinlich sind die Tafeln zu einem späteren Zeitpunkt, als die Thermen nicht mehr genutzt und die Denkmäler in Vergessenheit geraten waren, von hier fortgeschafft und als Baumaterial verwendet worden. Im 5. Jh. wurden in Ostia mehrere Depots mit alten Denkmälern und Architekturteilen angelegt. 664

Bleibt die Frage, wie man sich die Präsentation der Opistographen in den Thermen wird vorstellen dürfen. $\mathrm{Zu}$ beiden Seiten beschriftete Tafeln waren (nicht nur in der Spätantike) nichts Ungewöhnliches. Bei vielen derartigen Stücken rührte die doppelte Beschriftung von einer späteren Wiederverwendung her, das heißt die beiden Inschriften wurden unabhängig voneinander und in einem mehr oder minder großen zeitlichen Abstand angefertigt. Bei wieder anderen Tafeln scheint es sich bei einer der beiden Inschriften hingegen um einen ersten Entwurf oder einen missglückten Versuch gehandelt zu haben, den man mit einer verbesserten Version auf der anderen Seite wieder wettmachte. ${ }^{665}$ In unserem Fall trifft allerdings weder das eine noch das andere zu, denn zweifelsohne gehörten die Inschriften der beiden Tafelseiten zusammen und waren im selben Arbeitsschritt gefertigt worden. Ebenso sicher dürfen wir davon ausgehen, dass es sich bei keinem der Texte um einen Entwurf oder Fehlversuch handelt. Im Gegenteil: Angesichts der technisch sauberen und fehlerfreien Ausführung der einen wie der anderen Inschrift waren beide Seiten der Tafeln dazu konzipiert, gesehen zu werden, die Texte dazu, gelesen zu werden. Ihre Anbringung an einer Statuenbasis ist damit ausgeschlossen, da eine der beiden Inschriften auf diese

664 S. hierzu Pensabene 2004 und o. S.109f. Anm. 301.

665 Das Phänomen der Opistographe ist noch unzureichend untersucht, weshalb größere Studien hierzu bislang fehlen. Eingängiger mit diesem Thema hat sich I. di Stefano Manzella in seinem Werk zur Herstellung von römischen Inschriften befasst, wobei er sich bei seinen Erklärungsansätzen allerdings auf technische Aspekte, wie verschiedene Entwürfe und Fehlversuche, beschränkt: di Stefano Manzella 1987, 199-204; mit ähnlicher Betrachtung Carroll 2006, 118f. am Beispiel opistographer Tafeln mit Grabinschriften. 


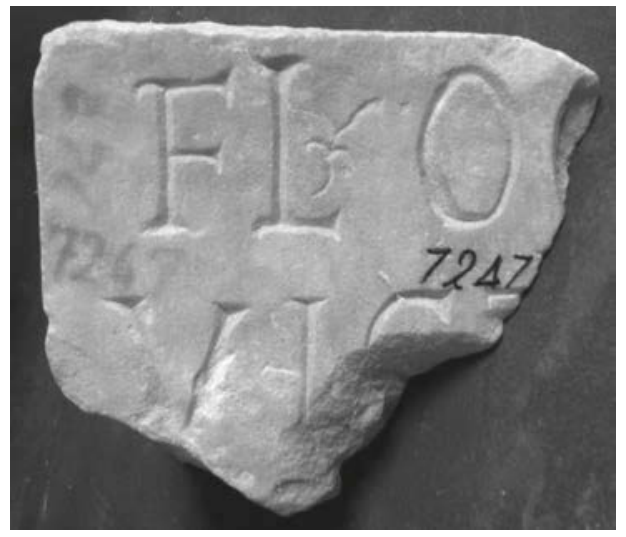

Abb. 81: Fragment eines Marmorblocks mit der Inschrift des Fl. Octavius Victor.

Weise verborgen geblieben wäre. Die Tafeln müssen also in anderer Form präsentiert worden sein, welche die Betrachtung beider Seiten ermöglichte. Denkbar wäre etwa, dass sie ähnlich einer Stele in unmittelbarer Nähe der jeweiligen Statue frei zur Aufstellung gekommen waren, was für derartige, auf Bildwerke Bezug nehmende Inschriften allerdings sehr ungewöhnlich wäre. Wahrscheinlicher erscheint hingegen, dass die Tafeln einst zu einer Brüstung oder Balustrade gehörten, welche die Wasserbecken im Frigidarium umgab und dekorativ einrahmte. ${ }^{666}$ Die dazugehörigen Statuen könnten direkt am Beckenrand oder in den gegenüberliegenden Wandnischen gestanden haben, sodass der Sichtbezug zwischen Inschrift und Bild nicht verloren ging.

3. Kleines Fragment eines Blocks aus weißem Marmor, gefunden innerhalb der Thermen, genaue Fundstelle unbekannt. Maße: $16 \times 15,5 \times 21,5 \mathrm{~cm}$, Buchstabenhöhe: ca. $4 \mathrm{~cm}$ (Abb. 81). ${ }^{667}$

Fl(avius) Oc[tavius] / Vict[or ---]

$\mathrm{Zu}$ welcher Art von Denkmal das Fragment gehörte, ist unklar. Die von Pietro Cicerchia und Alfredo Marinucci vorgeschlagene Zuweisung an einen Architrav erscheint in Anbetracht der geringen Buchstabenhöhe von lediglich vier Zentimetern aber recht unwahrscheinlich. Auch aufgrund der Anordnung der Inschrift in zwei sehr kurzen Zeilen wird man wohl eher an eine schmale, pfeilerartige Basis zu denken haben, welche einer Statuette oder einem dekorativen Wassergefäß als Postament diente.

666 Diese Idee äußerte zuvor schon F. Zevi (Zevi 1971, 466) und wurde später noch einmal von Alison Cooley aufgegriffen (Cooley 2013, 192).

667 Ohne Eintrag in CIL oder AE, publiziert bei Cicerchia/Marinucci 1992, 216 C 105; s. auch Zevi 1971, 467 n. 47; aufbewahrt im Museo Archeologico di Ostia (Inv.-Nr.: 7247). 


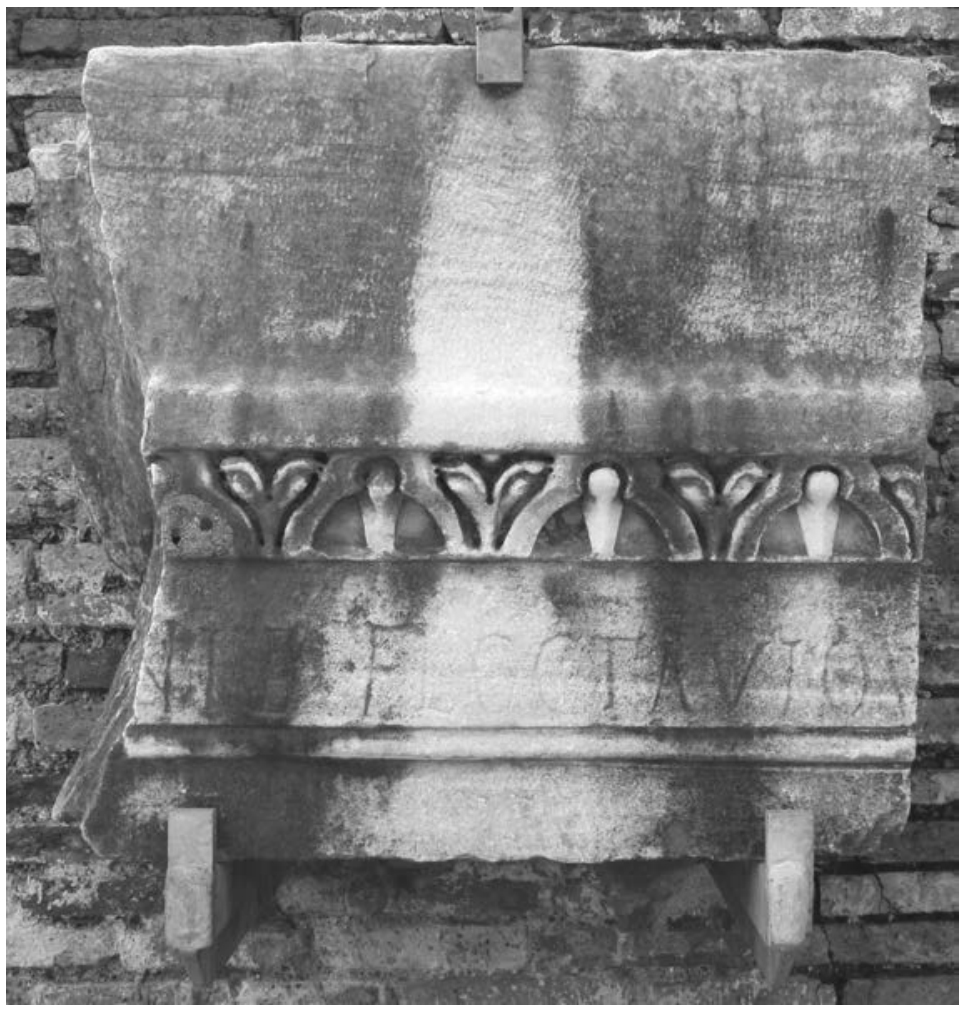

Abb. 82: Fragment eines wiederverwendeten Architravs aus den Forums-Thermen mit der Inschrift des Fl. Octavius Victor.

4. Fragment eines wiederverwendeten Drei-Faszien-Architravs mit lesbischem Kymation aus prokennesischem Marmor, Inschrift auf der mittleren Faszie, gefunden innerhalb der Thermen, genaue Fundstelle unbekannt. Maße: ca. 54,5 ×55×34/31 cm, Buchstabenhöhe: 5,2 cm (Abb. 82). ${ }^{668}$

[--- cura]nte Fl(avio) Octavio V[ictore v(iro) c(larissimo) praef(ecto) ann(onae)].

Bei dem Architrav handelt es sich um ein wiederverwendetes bzw. sekundär beschriftetes Stück aus den Forums-Thermen. Sowohl die Maße als auch die Ausführung der Architekturornamentik stimmen exakt mit denjenigen der noch in situ befindlichen Gebälkteile aus der ersten Bauphase der Anlage im 2. Jh. überein. ${ }^{669}$ Der Architrav gehörte wahrscheinlich zum Gebälk einer der Säulenreihen im Frigidarium.

668 Ohne Eintrag in CIL oder AE, publiziert bei Cicerchia/Marinucci 1992, 216 C 105, fig. 147; s. auch Zevi 1971, 466f., tav. I, 3; ausgestellt in den Forums-Thermen in Ostia (Inv.-Nr. 7025).

669 Dies konnte bei der Autopsie des Stücks vor Ort überprüft werden. 

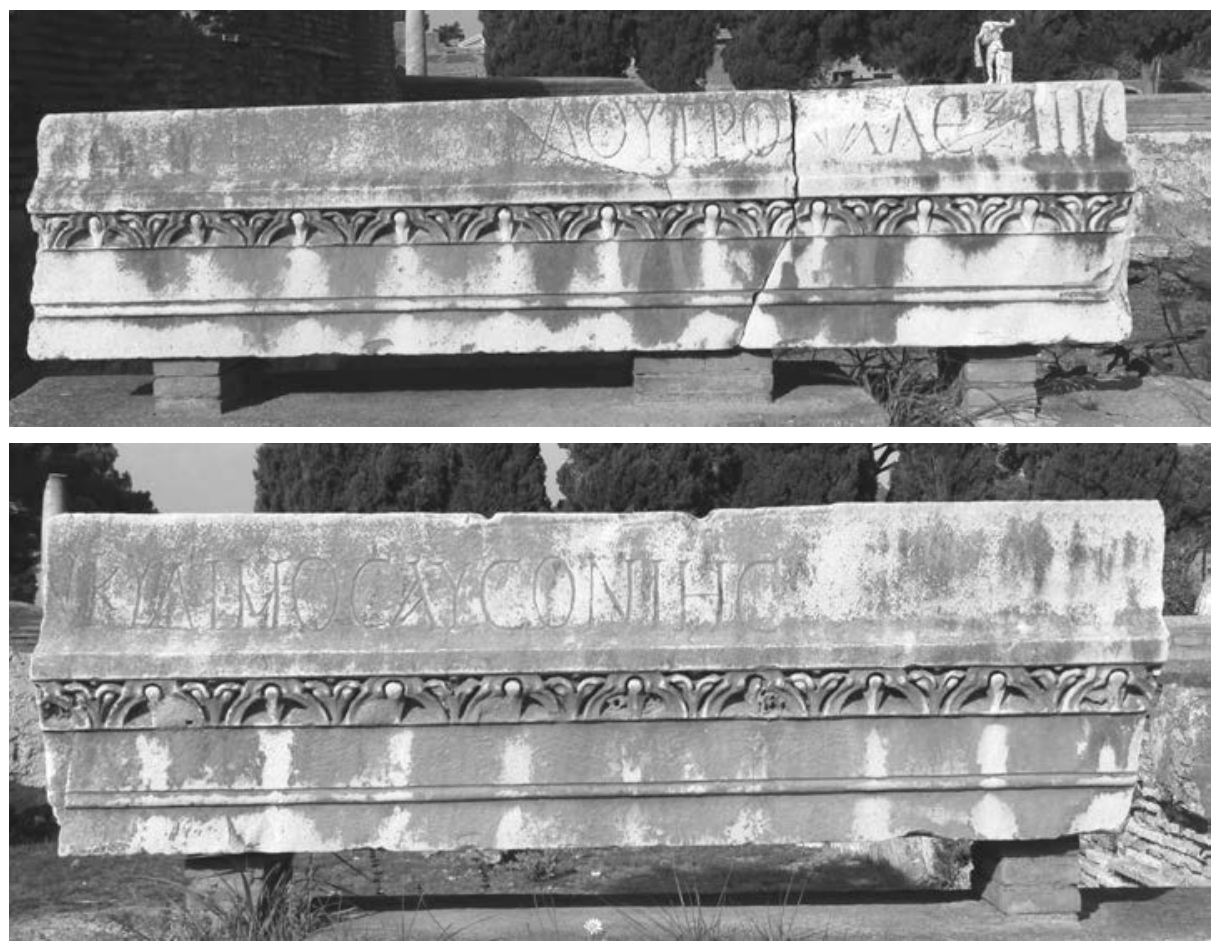

Abb. 83a-b: Wiederverwendeter Architrav aus den Forums-Thermen mit einem griechischen Epigramm des Fl. Octavius Victor.

5. Zwei Fragmente eines wiederverwendeten Drei-Faszien-Architravs mit lesbischem Kymation aus lunensischem Marmor, Inschrift auf der obersten Faszie, gefunden innerhalb der Thermen, genaue Fundstelle unbekannt. Maße: ca. 45/43×193,5×43/37 cm bzw. ca. $52 \times 172 \times 48,5 / 38 \mathrm{~cm}$, Buchstabenhöhe: ca. $10 \mathrm{~cm}$ (Abb. 83) ${ }^{670}$

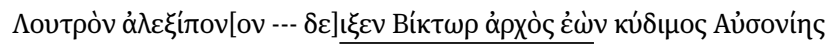

Wie die Maße und die stilistische Ausführung des Kymations verraten, hat man auch in diesem Fall auf einen bereits vorhanden Architrav der Thermenanlage zurückgegriffen und ihn für den aktuellen Anlass der Renovierung durch Victor neu beschriftet - ungewöhnlicherweise mit einem griechischen Epigramm. Die Inschrift ist nicht in vollem Umfang erhalten, da der mittlere Teil des Architravs fehlt. Dank der Beobachtungen von Russell Meiggs und Maria Letizia Lazzarini konnte aber wenigstens

670 IG 14, 1073 = SEG 33, 1983, 773 = ILCV 1901; Lazzarini 1983, 301-310; Cicerchia/Marinucci 1992, 219f. C 107, fig.149, 150; Cébeillac-Gervasoni/Caldelli/Zevi 2010, 151 Nr.28.2.4; ausgestellt in den Forums-Thermen in Ostia (Inv.-Nr. 7100a-b). 


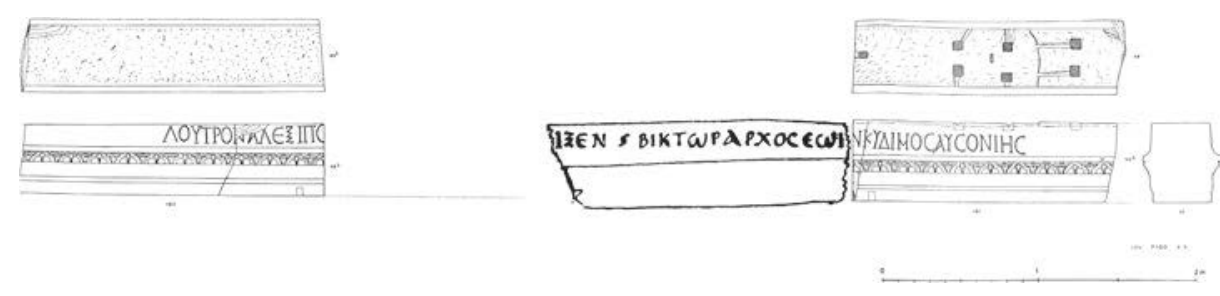

Abb. 84: Umzeichnung des Archtravs mit Ergänzung des Marini-Fragments.

ein Teil des Texts (hier unterstrichen) rekonstruiert werden. Die beiden erkannten in einer von Luigi Gaetano Marini im 19. Jh. angefertigten Zeichnung eines Architravfragments mit griechischer Inschrift die zwei in Ostia erhaltenen Bruchstücke wieder und ergänzten den zweiten Vers des lückenhaften Gedichts um das von Marini überlieferte Inschriftenfragment $\mathrm{zu}$ einem Hexameter (Abb. 84). ${ }^{671}$ Einen Vorschlag zur Lesung des ersten Verses machte zuletzt Stephan Busch, ${ }^{672}$ nach dem der vollständige Text abgefasst als ein griechisches Distichon - wie folgt gelautet haben könnte:

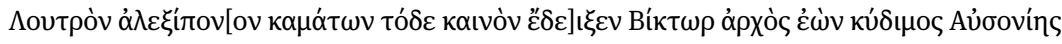

Dieses erneuerte Bad, welches die sorgenschwere Mühsal fernhält, brachte dar Victor, als er der ruhmvolle Anführer Ausoniens [d. h. Italiens] war.

Unter allen Inschriften Victors sticht diese in vielerlei Hinsicht hervor, zuerst aufgrund der griechischen Sprache und Schrift. Griechische Bauinschriften waren zu dieser Zeit (wie auch schon zuvor) im Westen des Römischen Reichs sehr selten. Inschriften, die Bau- oder Restaurierungsmaßnahmen an öffentlichen Gebäuden kommemorierten, wurden für gewöhnlich in Latein abgefasst und waren in der Regel auch nicht metrisch gestaltet. ${ }^{673}$ In ungewöhnlicher Art und Weise präsentierte sich diese Inschrift dem Thermenbesucher also in Griechisch, und noch dazu in einem literarisch anspruchsvollen Distichon. Ihre Sprache war eine poetische, statt des schlichten’I $\alpha \lambda$ í $\alpha$ wählte man das dichterische Aủooví $\alpha$. In diesem Sinn begegnete Victor auch nicht mit seinem vollständigen Namen und der üblichen römischen Titulatur, sondern lediglich mit seinem Cognomen, was nicht allein dem Metrum des Distichons, sondern auch dem Sprachstil des Epigramms Rechnung trug. ${ }^{674}$ Man wird sich den Architrav wohl eben-

671 Meiggs 1960, 475; Lazzarini 1983. Für die Zeichnung Marinis s. Vatic. Lat. 9071, Nr.6. Der Fund wurde erstmals von A. Mai 1831 vorgelegt (Scriptorum veterumnova collectio e Vaticanis codicibus edita V, Roma 1831, 348 Nr. 5), später noch einmal publiziert in IG XIV 1073b. Das Stück ist heute verloren. 672 Busch 1999, $121 \mathrm{f}$.

673 Tatsächlich sind vergleichbare Zeugnisse, also in der Spätantike neu verfasste griechische Versinschriften an öffentlichen Bauwerken wie Thermen, im Westen des Römischen Reichs m. W. nicht bekannt.

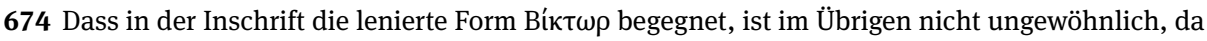
sich die Verwendung des griechischen B für das lateinische V zu dieser Zeit längst durchgesetzt hatte. 
falls auf einer der Säulenreihen im Frigidarium vorstellen dürfen, vielleicht über derjenigen des nördlichen Beckens mit dem apsidialen Abschluss, dessen Spannweite er mit einer rekonstruierten Gesamtlänge von rund neun Metern sehr genau entspricht.

Den fünf Inschriften des Flavius Octavius Victor stehen drei mit dem Namen des Ragonius Vincentius Celsus gegenüber. Sie alle folgen dem gleichen Wortlaut:

Curavit Ragonius Vincentius Celsus v(ir) c(larissimus) praefectus annonae urbis Romae et civitas fecit memorata de proprio.

Dies besorgte Ragonius Vincentius Celsus, vir clarissimus, praefectus annonae urbis Romae, und die Gemeinde ließ es aus ihren Finanzen machen.

hieß es sowohl auf einem Architrav als auch auf zwei Statuenbasen, von denen sich die eine noch immer an ihrem Fundort vor den Thermen befindet, die andere heute in den Vatikanischen Museen zu sehen ist. Ragonius Vincentius Celsus, so die inhaltliche Aussage des Texts, trug in seiner Rolle als römischer Stadtpräfekt für die Baumaßnahmen Sorge, während die Bürgerschaft Ostias für deren Finanzierung aufkam.

1. Fünf Fragmente eines Drei-Faszien-Architravs aus grauem Marmor, ohne Dekor, Inschrift auf der mittleren Faszie, gefunden zum Teil in Raum 1 der Forums-Thermen, zum Teil in einer spätantiken exedra an der Semita Horreorum. Maße: mind. 468 x ca. $24 \times 40 \mathrm{~cm}$, Buchstabenhöhe: $5-6 \mathrm{~cm}$ (Abb. 85, 86). ${ }^{675}$

Curavit Ragonius Vincentius Celsus v(ir) c(larissimus) praefectus annonae urbis Romae et civitas fecit me[morata de propri]o.

Anders als im Fall der Inschriften des Flavius Octavius Victor war dieser Architrav nicht wiederverwendet worden. Er gehörte jedenfalls nicht zum ursprünglichen Gebälk der Forums-Thermen, von dem er sich sowohl im Hinblick auf die Marmorsorte als auch auf die Maße und die Formgebung unterschied. Mit einer Höhe von etwa 24 Zentimetern ist er wesentlich kleiner und zeigt auch keine dekorativen Elemente und Zierleisten. Wie mehrere Einkerbungen für die Anbringung von Metallklammern an der Unterseite nahelegen, wurde er von vier Säulen oder Pilastern getragen. Für seine Anbringung kommt am wahrscheinlichsten der von Celsus neu gestaltete Eingangsbereich (Raum 1) in Frage, wo er entweder einen der beiden Zugänge an der dem Forum zugewandten Westseite oder denjenigen an der Südseite überspannte, der sich dem vom decumanus kommenden Besucher anbot (Abb.90).

675 CIL XIV 4718; Calza 1927, 399f.; Zevi 1971, 465f.; Cicerchia/Manucci 1992, 165f. C 1; Gering 2011b, 489; ausgestellt in den Forums-Thermen ausgestellt (Inv.-Nr.19734; 7026). - Die in der exedra zum Vorschein gekommenen Fragmente des Architravs waren wohl aufgrund ihres Materialwerts hierher geschafft worden. Das Areal diente einst als Bäckerei und beherbergte einen Ofen, der seit dem 5. Jh. offenbar für die Herstellung von Kalk genutzt wurde; s. hierzu Gering 2004, 321-341. 

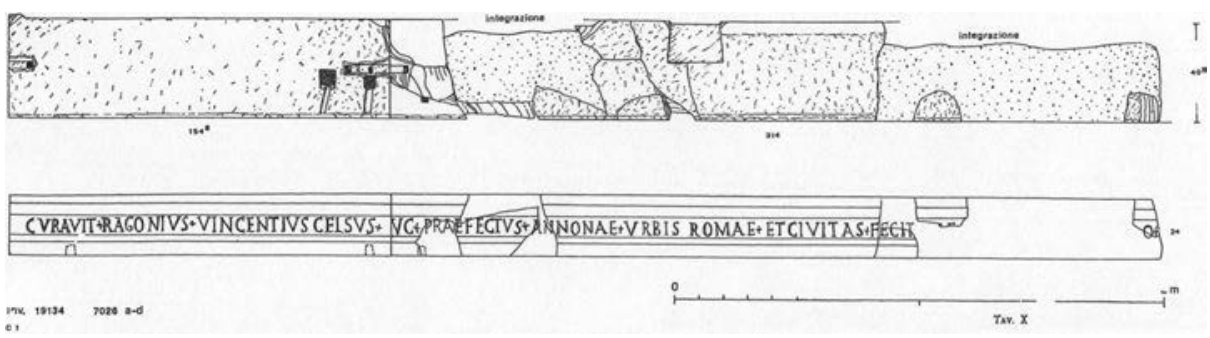

Abb. 85: Architrav aus den Forums-Thermen mit der Inschrift des Ragonius Vincentius Celsus, Umzeichnung.
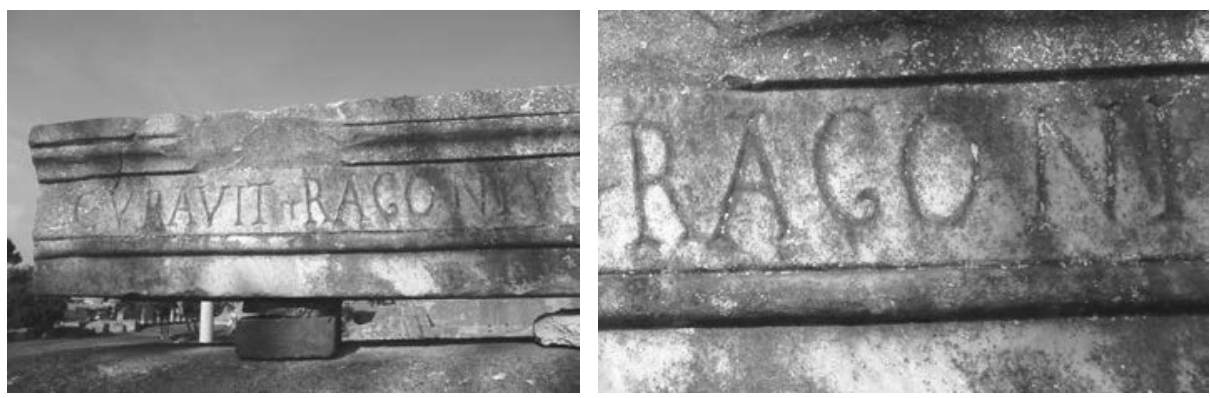

Abb. 86a-b: Detailaufnahmen des Architravs.

2. Wiederverwendete Statuenbasis aus weißem Marmor, gefunden an der Ostseite des Forums, dort noch in situ. Maße: ca. $135 \times 63 / 69 \times 50,5 \mathrm{~cm}$, Buchstabenhöhe: 5,5-6 cm. Die rechte obere Ecke der Basis ist stark bestoßen, auf der Oberseite sind Spuren von zwei Dübellöchern für die Anbringung einer Bronzestatue zu erkennen (Abb. 87). ${ }^{676}$

Curavit Ragoniu[s] / Vincentius Celsus / v(ir) c(larissimus) praefectus / annonae urbis / Romae, [[et]] civitas / fecit memorata /de proprio.

3. Wiederverwendete Statuenbasis aus weißem Marmor, aus Ostia, genauer Fundort unbekannt, heute in den Vatikanischen Museen ausgestellt. Erhalten ist nur die Front. Maße: $90 \times 58 \mathrm{~cm}$, Buchstabenhöhe: $4-5 \mathrm{~cm}$ (Abb. 88) ${ }^{677}$

Curavit Ragonius / Vincentius Celsus / v(ir) c(larissimus) praefectus / annonae urbis / Romae et civitas / fecit memorata /de proprio.

676 CIL XIV 4717 = AE 1928, 131 = LSA 2582; Calza 1927, 399; Cicerchia/Manucci 1992, 166f. C 1b.

677 CIL XIV 139 = LSA 1651; Cicerchia/Manucci 1992, 166 C 1a; ausgestellt im Museo Pio Clementino, Sala della Muse. 


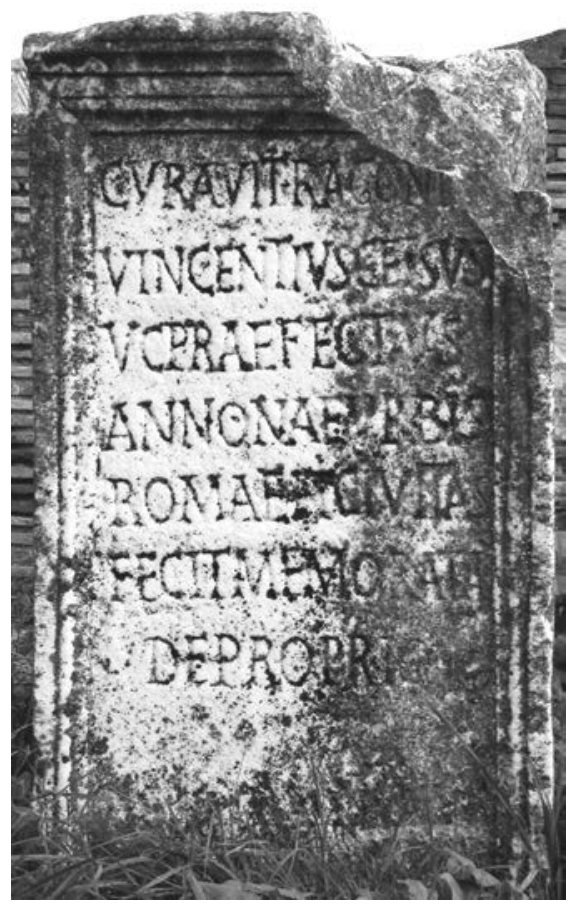

Abb. 87: Wiederverwendete Statuenbasis mit der Inschrift des Ragonius Vincentius Celsus, gefunden am Ostrand des Forums, dort noch in situ (CIL XIV 4717).

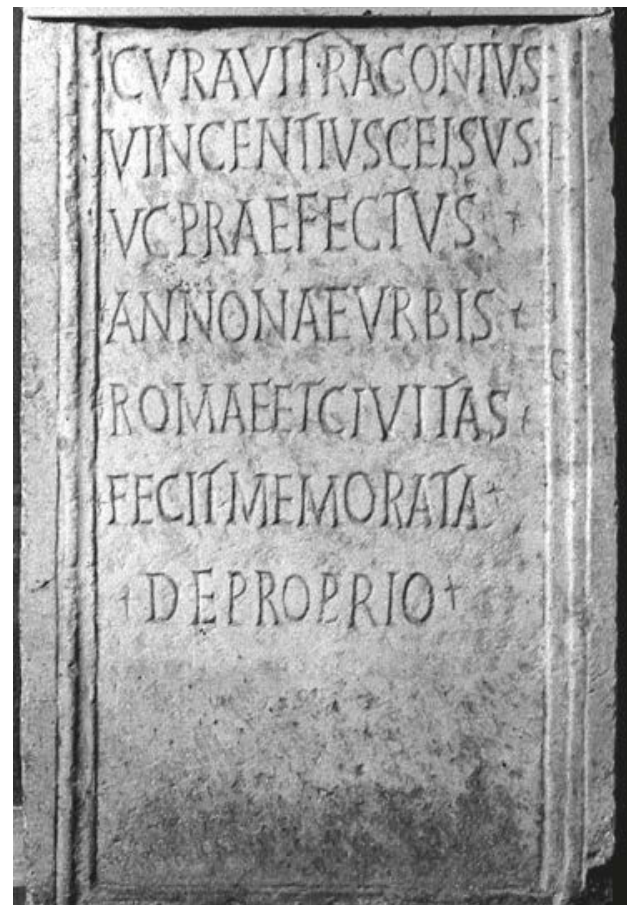

Abb. 88: Zweite wiederverwendete Statuenbasis mit gleichlautender Inschrift des Ragonius Vincentius Celsus, aus Ostia, heute in den Vatikanischen Museen (CIL XIV 139).

Die Inschriften auf den beiden Basen sind sehr ähnlich gestaltet. Beide sitzen in einem doppelt gerahmten Inschriftenfeld, in welchem sich der Text in sieben jeweils genau gleich angeordneten Zeilen erstreckt. Offenbar gehörten beide Stücke zu einem Auftrag und wurden in derselben Werkstatt hergestellt. Sie stammen allerdings wohl nicht von derselben Hand, wie es kleine Unterschiede in der Gestaltung einzelner Buchstaben (wie im Fall des L, R oder T) sowie die Hinzufügung kleiner dekorativer Kreuze am Zeilenbeginn und -ende bei dem Stück im Vatikan vermuten lassen. Ferner sind beide Basen wiederverwendete Postamente älterer Denkmäler, deren Inschriften man ausgemeißelt und durch die neuen mit dem Namen des Ragonius Vincentius Celsus ersetzt hat. Hier wie da sind an den Rahmen noch einige Buchstaben der älteren Inschriften zu erkennen, die nicht vollständig entfernt wurden.

Die auf den Basen präsentierten Bildwerke sind verloren und allein mit Blick auf den Inhalt des Texts nicht mehr zu rekonstruieren, denn dieser geht lediglich auf die Rolle des Celsus als zuständiger Aufseher über die Baumaßnahmen und auf die Gemeinde Ostias als Geldgeber ein. Dass es sich um Bildnisse des Celsus selbst 


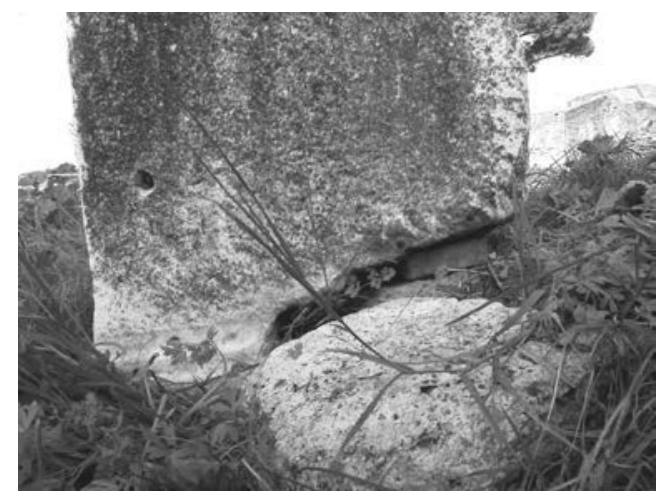

Abb. 89: Basis vom Forum, Detail der Abarbeitungen an der rückwärtigen Unterseite.

gehandelt hat, wie es hin und wieder vermutet wurde, ${ }^{678}$ ist auszuschließen. Ehrenstatuen konnten nicht selbst initiiert werden, sondern wurden dem Geehrten von Institutionen oder Körperschaften errichtet. Auch das Formular wäre in diesem Fall sehr ungewöhnlich. Der Typus der ,curavit-Inschrift‘ war seinerzeit nicht im Zusammenhang mit öffentlich aufgestellten Ehrenbildnissen, sondern in Verbindung mit Statuenaufstellungen bzw. -wiedererrichtungen geläufig. Exemplare dieser Art sind etwa auf dem Forum Romanum in großer Zahl erhalten, wo sich insbesondere die Stadtpräfekten durch die erneute Aufstellung älterer Statuen verdient gemacht hatten. ${ }^{679}$ Gleiches scheint für unseren Fall in Ostia zu gelten: Die Basen stammten von Denkmälern vergangener Tage, die anlässlich der Renovierungsmaßnahmen durch Celsus noch einmal zur Aufstellung gebracht wurden - Bilder von Göttern und mythischen Gestalten sind ebenso denkbar wie von Athleten oder Idealfiguren. Die Praxis der Wiedererrichtung älterer Denkmäler war in der Spätantike nichts Ungewöhnliches und ist gerade für Ostia gut belegt, etwa durch eine Basis, deren Inschrift erklärt, die entsprechende Statue sei von einem verödeten Ort auf das Forum gebracht worden, um dieses durch seine Anwesenheit zu verschönern. ${ }^{680}$ Dass die Statuen auf den beiden Basen von den Thermen im Zuge der Neubeschriftung durch Celsus nicht ausgetauscht wurden, belegt auch der Zustand der Oberseite der Ostienser Basis. Auf dieser lassen sich neben den beiden erwähnten Dübellöchern nämlich keine weiteren Spuren einer zweiten Statuenanbringung ausmachen.

Angesichts der gleichartigen Gestaltung der Inschriften - sowohl was den Text als auch seine Anordnung auf dem Stein angeht - waren die Denkmäler wohl gemeinsam aufgestellt, sodass sie sich dem Betrachter als zusammengehöriges Paar präsentierten. Da die Basis auf dem Forum an ihrer rückwärtigen Unterseite stufenartige Abarbeitungen zeigt, als sei sie nachträglich für die Aufstellung auf einer Treppe umgestaltet worden (Abb. 89), scheint die Mündung der Via della Forica, zwischen der

678 So zuletzt etwa Boin 2013, 148.

679 Zum Beispiel CIL VI 1653, 1655, 1657, 1667, 1669.

680 CIL XIV 4721; zu dem Stück s. o. S. 216. 


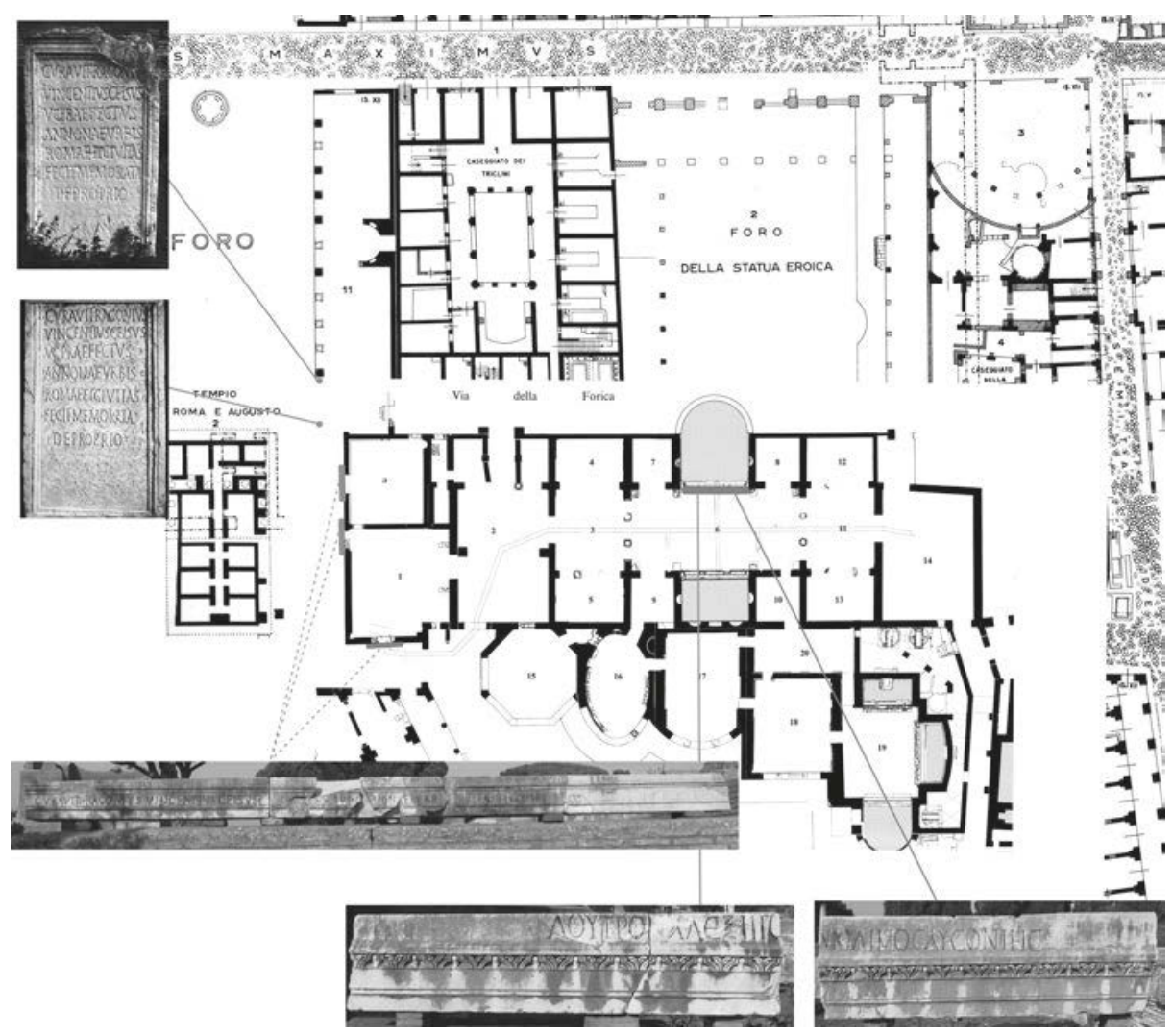

Abb. 90: Grundriss der Forums-Thermen mit Verteilung der Inschriften.

Forumsportikus und dem neu gestalteten Eingangsbereich der Thermenanlage, der wahrscheinlichste Aufstellungsort zu sein. Während die eine Basis etwas erhöht auf den Stufen der Portikus stand, war die andere auf der gegenüberliegenden Seite direkt vor der Fassade der Thermen aufgestellt (Abb. 90).

\subsection{Die Botschaften: Habitus und Rollenerwartungen}

Die beiden Inschriften-Ensembles des Flavius Octavius Victor und des Ragonius Vincentius Celsus waren auf bezeichnende Art und Weise unterschiedlich - und dies nicht nur im Hinblick auf ihre inhaltliche Gestaltung, sondern kaum weniger auffällig auf der Ebene ihrer materialen Präsenz. Im Zusammenspiel mit der textlichen Aussage der Inschriften verliehen ihr spezifisches Erscheinungsbild und ihre absichtsvolle Präsentation den Monumenten eine jeweils eigene Kontur und waren für die mit ihnen verbundenen Botschaften von bestimmender Bedeutung. 
Die Inschriften des Victor zeichneten sich - wenigstens im Fall des GlaukeEpigramms und des griechischen Distichons des Architravs - nicht nur durch eine anspruchsvolle Textgestaltung in Versen und durch einen dichterischen Sprachstil aus. Sie waren auch von hoher handwerklicher und künstlerischer Qualität, wie es insbesondere an den gut erhaltenen Inschriften der Opistographen und des kleinen Marmorfragments nachzuvollziehen ist: Um eine gleichmäßige mise-en-page auf dem Inschriftenfeld zu garantieren, wurden zunächst feine, kaum sichtbare Hilfslinien gezogen, auf denen die Buchstaben dann in sehr regelmäßigen Abständen angeordnet wurden. Bei der curavit-Inschrift der Marmortafel hat man sich dabei für eine besondere Variante entschieden, bei der die Zeilen nach unten hin immer größer wurden. ${ }^{681}$ Die einzelnen Buchstaben wurden sehr gewissenhaft eingemeißelt und zeigen ein ausgeprägtes Licht-Schatten-Spiel, das durch die Anwendung einer speziellen Meißeltechnik mit keilförmigem Schnitt erzielt wurde und vom handwerklichen Geschick des Steinmetzen zeugt. Ausgewogene Buchstabenformen und die Hinzufügung kleiner Interpunktionszeichen in Form stilisierter Zweige runden das Bild einer ebenso gewissenhaften wie anspruchsvollen Ausführung ab. Und nicht zuletzt deutet auch die Wahl des feinen weißen Marmors als Inschriftenträger in die gleiche Richtung: Bei den Stücken des Victor war man um ein ansprechendes, jedenfalls um ein niveauvolles Erscheinungsbild bemüht, das den hohen Anspruch des Auftraggebers offenbaren sollte. Die in griechischen Lettern abgefasste Inschrift machte in dieser Hinsicht keine Ausnahme. Auch hier legte man Wert auf einen harmonischen Gesamteindruck und wählte für einzelne Buchstaben, etwa das A und $\Xi$, besonders kreative Formen. Vor allem die in Versform abgefassten Inschriften waren im Zusammenspiel mit dem elegant wirkenden Schriftbild ein im Hinblick auf die mit ihnen verbundene Botschaft ein aussagekräftiges Medium der persönlichen Repräsentation. Mit ihrer Hilfe konnte sich Victor als ein Mann von kulturellem Anspruch, Bildung und ästhetischer Empfindsamkeit profilieren.

In kaum einem anderen Monument hätte sich ein solches Selbstverständnis besser widerspiegeln können als in dem griechischem Epigramm auf dem Architrav des Frigidariums. Der Anblick des Stücks muss bei den meisten Besuchern des Bads zunächst Verblüffung und manches Mal auch Ratlosigkeit ausgelöst haben. Denn dass ein Bauherr seine Initiative mit einem griechischen Gedicht öffentlich festhalten ließ, war, wie gesagt, nicht nur ungewöhnlich, sondern nachgerade exzeptionell. Und auch wenn das griechische Alphabet vielen Bewohnern der ehemaligen Handelsstadt Ostia nicht unbekannt gewesen sein dürfte, so verstanden sich sicherlich nicht alle darauf, die Verse zu lesen und zu verstehen. Doch auch wenn nur ein kleiner Kreis von gebil-

681 Diese Anordnung des Texts könnte mit einer Aufstellung der Tafel auf Bodenniveau zu tun haben. Indem die Zeilen nach unten hin immer höher und die Buchstaben damit immer größer wurden, entstand dem von schräg oben auf die Tafel blickenden Betrachter der Eindruck eines gleichmäßig hohen Schriftbilds. Die Anbringung der Tafel an der Brüstung eines Badebeckens ist vor diesem Hintergrund also sehr gut vorstellbar. 
deten und belesenen Betrachtern dazu in der Lage war, so muss dies nicht bedeutet haben, dass sich die Inschrift allein an sie richtete. Denn auch vollkommen illiterate Besucher hatten sie ja wahrgenommen und sicherlich auch als das zu deuten gewusst, was sie im Wesentlich war: ein Denkmal zur Erinnerung an die Renovierung des Bads. Sollte sie tatsächlich zu der nördlichen Säulenreihe des Frigidariums gehört haben, also des Zentrums der Anlage mit der gerade erst neu gestalteten Apsis, war es unmöglich, nicht von ihr Notiz zu nehmen. Und auch wenn der Text nicht von jedem Betrachter vollständig erfasst und in seinem literarischen Wert gewürdigt werden konnte, so hinterließ die auffällige Inschrift doch in jedem Fall auf der Ebene ihrer materialen Präsenz Eindruck - und dieser mochte womöglich nachhaltiger gewesen sein als der Inhalt des Texts selbst. Auch zur Zeit des Victor brachte man der griechischen Kultur in Rom große Bewunderung entgegen, und insbesondere unter römischen Aristokraten und Mitgliedern der gebildeten Oberschichten genossen die Werke griechischer Künstler und Dichter hohes Ansehen. Sich als Liebhaber und Kenner der hellenischen Kultur einen Namen zu machen, versprach gesellschaftliche Anerkennung und soziales Prestige, weshalb man sich in den entsprechenden Kreisen gerne mit griechischer Kunst umgab, sich den Werken der griechischen Literatur widmete und sich in griechischer Tracht zeigte, also: den Habitus des römischen Philhellenen pflegte. ${ }^{62}$ So offenbar auch Victor, der sich im Spiegel seiner Inschriften nicht nur als Bauherr in seiner Rolle als zuständiger Magistrat, sondern darüber hinaus als kultivierte Persönlichkeit und Bewunderer des Hellenentums darzustellen suchte.

Diese Rolle scheint Ragonius Vincentius Celsus hingegen nicht für sich in Anspruch genommen zu haben. Seine Inschriften sprechen eine andere Sprache, sowohl auf der materialen Ebene der Denkmäler wie auch auf der inhaltlichen Ebene des immer gleich lautenden Texts, der auch im Zusammenhang mit verschiedenen bildlichen und räumlichen Kontexten keine Varianz erfuhr. Im Gegenteil: Konformität war hier offenbar gezielt gesucht und auch in Verbindung mit unterschiedlichen Monumenten und Anbringungssituationen nicht aufgegeben worden, und dies, obgleich man sich insbesondere im Fall der Bauinschrift auch für eine andere, ausführlichere Formulierung hätte entscheiden können. Diese hätte zum Beispiel die durchgeführten Baumaßnahmen näher bestimmen und einen konkreten Anlass benennen können, wie es in der Spätantike häufig geschehen ist und wie man es etwa auch bei der eingangs erwähnten Restaurierungsinschrift des 4. Jhs. mit dem Namen des Marcus Gavius Maximus getan hat. Das Festhalten am Prinzip der Einheitlichkeit lässt sich auch mit Blick auf die materiale Gestaltung der Inschriften beobachten, deren Schrift-

682 Zur Affinität der römischen Oberschicht zur griechischen Kultur s. Ferray 1988; Rochette 1999; Anderson 1993; Hölscher 1994; Follet 2004. Dazu passt im Übrigen auch die Beobachtung, dass sich viele Statthalter des 4. Jhs. in ihren Bildnissen im Habitus des Intellektuellen darstellen ließen. Zu den Merkmalen solcher Porträts zählten ein ,vergeistigter Gesichtsausdruck ' mit ernsten Blick und zusammengezogenen Brauen, Barttracht und Himation. In den Inschriften werden sie häufig als begabte Redner und für ihre hohe Bildung gefeiert; s. hierzu Brown 1992; Gehn 2012, 288-292. 
bild, Modulus und Duktus einander auffallend ähnlich sind. Am deutlichsten schlägt sich dies in der absolut identischen Anordnung des Texts in sieben zentriert platzierten Zeilen auf den beiden Statuenbasen nieder. Ferner lässt aber auch die Ausformung der einzelnen Buchstaben kaum Abweichungen voneinander erkennen. Auch wenn bei der vatikanischen Basis die Serifen etwas ausgeprägter oder die Deckstriche etwas stärker geschwungen sind als bei dem Stück in Ostia - dem gewünschten Gesamteindruck der Homogenität tat dies keinen Abbruch, und auch die Inschrift des Architravs fügt sich angesichts der gleichen Buchstabenformen (besonders auffällig beim $\mathrm{G}$ und L) und Interpunktionszeichen in Form kleiner Kreuze ohne Weiteres in dieses Bild ein.

Man wüsste gerne, wo genau im neu gestalteten Eingangsbereich die drei Inschriften des Celsus aufgestellt waren und ob ein direkter Sichtbezug zwischen dem Basenpaar und dem Architrav bestand. Wenn dem so war - und dafür scheint, wie oben angedeutet, Vieles zu sprechen -, so hätte sich der Betrachter einem ebenso auffallenden wie einprägsamen Inschriften-Ensemble gegenüber gesehen, das seine Wirkung durch demonstrative Konformität und plakative Homogenität entfaltete. So oder so, in jedem Fall konnten sich die Inschriften Aufmerksamkeit gewiss sein. Anders als diejenigen des Victor waren sie nicht innerhalb der Thermenanlage, sondern an bzw. vor der Eingangsfassade aufgestellt, wo nicht nur die eintretenden Badegäste, sondern auch die Passanten des Forums und der Via della Forica von ihnen Notiz nehmen konnten. So mochten die Inschriften des Celsus nicht nur ein größeres Publikum erreicht haben, sondern auch ein breiteres. Denn anders als das griechische Epigramm des Victor verlangten ihm seine lateinischen Inschriften mit ihrem gewohnten Alphabet und dem gut bekannten Formular keine besonderen Fähigkeiten und Kenntnisse ab, wie sie nur gebildete Leute bestimmter gesellschaftlicher Kreise besaßen, und waren auch für wenig geschulte Leser ohne größere Schwierigkeiten zu verstehen. Ohnehin ging ihnen der elitäre Charakter der Inschriften des Victor ab. Ihnen fehlte nicht nur deren literarischer Anspruch, sondern auch der ästhetische. Bei den beiden Basen handelt es sich um wiederverwendete Stücke, deren ursprüngliche Inschriften zum Teil sogar noch sichtbar waren. ${ }^{63}$ Die einzelnen Buchstaben waren zwar technisch sauber und fehlerfrei in den Stein gehauen, verfügten aber nicht über die gleiche Eleganz wie diejenigen bei den Stücken des Victor. Und schließlich hat man auch auf dekorative Elemente verzichtet und sich für einen blanken Architrav ohne Schmuckornamentik entschieden.

Der weithin gebräuchliche, leicht zugängliche Text, das schlichte, aber umso prägnantere Erscheinungsbild und die publikumswirksame Präsentation der Inschriften vor der Fassade der Thermen zeichneten so ein ganz anderes Bild als im Fall des Victor. Celsus erscheint vor allem als pflichtbewusster Magistrat, der seiner Rolle als Verantwortlicher für den Umbau der Thermen gerecht wurde, sich darüber hinaus aber nicht

683 Vorausgesetzt, dass das Schriftfeld nicht mit Stuck überdeckt wurde, wie es bei wiederverwendeten Basen durchaus vorgekommen sein könnte. 
weiter zu profilieren suchte. Die Wendungen seiner Inschriften waren den Bürgern vertraut und entsprachen den Konventionen ihrer Zeit. Die Texte waren ebenso konzis wie zweckdienlich. Gleiches gilt für die Monumente. Auch sie waren nicht aufwendiger gestaltet als notwendig. Insbesondere in der Gegenüberstellung mit den Denkmälern des Victor fühlt man sich bei ihnen an traditionelle römische Werte wie Pflichtgefühl (pietas) und Bescheidenheit (modestia) erinnert und glaubt den Habitus des verantwortungsvollen römischen Beamten zu erkennen, der seinem Auftrag zum Wohle der Gemeinschaft nachkam - nicht umsonst ist in den Inschriften des Celsus die Gemeinde von Ostia als Finanzier der Baumaßnahmen erwähnt. So verschafften sich in den Ensembles des Victor und des Celsus zwei sehr verschiedene Strategien persönlicher Repräsentation Ausdruck, mit denen verschiedene Rollenbilder bedient und unterschiedliche Botschaften versendet wurden: Individualität und die offene Zurschaustellung persönlicher Vorlieben auf der einen, treue Pflichterfüllung und ein Bekenntnis zu traditionellen römischen Werten auf der anderen Seite.

Ob dies dem zeitgenössischen Beobachter beim Betrachten der Denkmäler bewusst war, können wir nicht wissen, und es steht zu vermuten, dass er kaum einen Gedanken an die materiale Dimension der Inschriften und die Bedeutung ihrer Präsenz verschwendet hat. Vollkommen unbeeindruckt dürften ihn die Inschriften aber auch nicht gelassen haben. Davon zeugt jedenfalls eine Episode in den Confessiones des Kirchenvaters Augustinus, der Ostia zusammen mit seiner Mutter Monica im Jahr 387 besuchte. Als diese dort unerwartet verstarb, konnte Augustinus zunächst keinen Trost finden und gab sich ganz seiner Trauer hin. Doch dann, so berichtet er: „Ich kam auf den Gedanken, ein Bad zu nehmen, weil ich gehört hatte, dass der aus dem Griechischen stammende Name - balneum von balaneion - bedeute, dass es den Kummer vertreibe“. ${ }^{684}$ Ganz offenbar hatte Augustinus die Forums-Thermen besucht und war dort auf das griechische Epigramm des Victor aufmerksam geworden. Der Anblick der Inschrift blieb ihm so nachhaltig in Erinnerung, dass er nicht vergaß, dies in seinen Aufzeichnungen festzuhalten.

684 August. Conf. IX 32: Visum etiam mihi est, ut irem lavatum, quod audieram inde balneis nomen inditum, quia Graeci balaneion dixerint, quod anxietatem pellat ex animo. Übersetzung nach ed. Thimme 2004, 413, 415. 
